\title{
Pseudoaneurysm of the brachial artery in a patient who uses intravenous drugs
}

\author{
Adam Kovacs-Litman MD, Wayne L. Gold MD
}

Cite as: CMAJ 2021 March 29;193:E448. doi: 10.1503/cmaj.201843

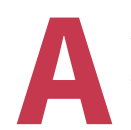

39-year-old man who used intravenous fentanyl presented to the emergency department with a 1-month history of a painful, progressively enlarging pulsatile mass in his right antecubital fossa (Figure 1). He did not report fever. We auscultated a bruit over the mass and suspected an aneurysm. We ordered computed tomography angiography and Doppler ultrasonography of the patient's right arm. The findings were consistent with a pseudoaneurysm of the brachial artery with retained needle fragments (Appendix 1, available at www.cmaj.ca/lookup/doi/10.1503/ cmaj.201843/tab-related-content). We made a presumptive diagnosis of an infected (mycotic) pseudoaneurysm.

After ordering 3 sets of blood cultures, from which no organism was grown, we prescribed empiric therapy with vancomycin and piperacillin-tazobactam, which was transitioned after several days to amoxicillin-clavulanate $(875 \mathrm{mg} / 125 \mathrm{mg}$ administered orally every $12 \mathrm{~h}$ ) for a total of 4 weeks. The pseudoaneurysm was bypassed surgically. Potentially infected tissue and needle fragments were left in situ because of the high operative risk associated with their removal. Our patient recovered uneventfully.

The term pseudoaneurysm describes a collection of blood that is not bounded by all 3 layers of the arterial wall; the cause is usually trauma, which may include intravenous drug use. ${ }^{1}$ In this setting, infection may occur through direct inoculation of microorganisms into the vessel wall or via seeding of a pre-existing pseudoaneurysm through the systemic circulation. ${ }^{2}$ Mycotic pseudoaneurysms classically present as painful, pulsatile, enlarging masses with local signs of infection. In 1 case series involving 50 patients with mycotic aneurysms secondary to intravenous drug use, the following findings were reported: fever $(48 \%)$, a tender indurated mass $(92 \%)$, a pulsatile mass $(52 \%)$ and presence of a bruit $(48 \%){ }^{2}$ Results for blood cultures are positive in $50 \%-85 \%$ of cases. ${ }^{3}$

Management comprises antibiotic therapy and surgical intervention, including excision when possible, and revascularization as required. ${ }^{2}$ Differentiating mycotic pseudoaneurysms, particularly when not pulsatile, from abscesses, is important because attempted incision and drainage of a pseudoaneurysm can result in catastrophic hemorrhage.

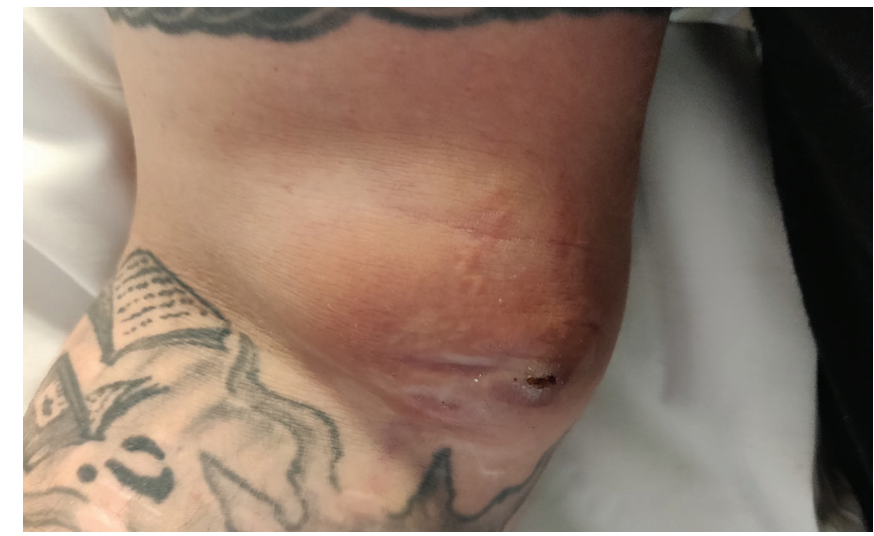

Figure 1: Right arm of a 39-year-old man who uses intravenous drugs showing a pulsatile mass ( $8 \mathrm{~cm}$ in diameter) superior to the antecubital fossa with a visible puncture site and overlying erythema.

\section{References}

1. Regus S, Lang W. Rupture risk and etiology of visceral artery aneurysms and pseudoaneurysms: a single-center experience. Vasc Endovascular Surg 2016;50:10-5.

2. Johnson JR, Ledgerwood AM, Lucas CE. Mycotic aneurysm. New concepts in therapy. Arch Surg 1983;118:577-82.

3. Maeda $\mathrm{H}$, Umezawa $\mathrm{H}$, Goshima M, et al. Primary infected abdominal aortic aneurysm: surgical procedures, early mortality rates, and a survey of the prevalence of infectious organisms over a 30-year period. Surg Today 2011; 41:346-51.

\section{Competing interests: None declared.}

This article has been peer reviewed.

The authors have obtained patient consent.

Affiliations: Department of Medicine (Gold, Kovacs-Litman), University of Toronto; Divisions of General Internal Medicine and Infectious Diseases (Gold), University Health Network, Toronto, Ont.

Content licence: This is an Open Access article distributed in accordance with the terms of the Creative Commons Attribution (CC BY-NCND 4.0) licence, which permits use, distribution and reproduction in any medium, provided that the original publication is properly cited, the use is noncommercial (i.e., research or educational use), and no modifications or adaptations are made. See: https://creativecommons.org/ licenses/by-nc-nd/4.0/

Correspondence to: Adam Kovacs-Litman, adam.kovacslitman@ mail.utoronto.ca 